\title{
Prevalence of noise induced hearing loss among employees at a mining industry in Zimbabwe
}

\author{
*Chadambuka A, Mususa F, Muteti S \\ Department of Community Medicine, University of Zimbabwe
}

\begin{abstract}
Background: Noise induced hearing loss (NIHL) is within the top five occupational illnesses in Zimbabwe. Workers at a mining company complained about loss of hearing at the mine clinic.

Objective: To determine the prevalence of NIHL among employees at the Mine.

Methods: We conducted a descriptive cross sectional study at the mine. Workers were proportionally selected to represent all the mine departments or working areas. We measured noise levels at various mine sites, conducted a walk-through survey to observe noise related worker practices and conducted audiometric testing.

Results: Mean age for workers was $34.8 \pm 7.6$ years and the mean duration of exposure to noise was $7.5 \pm 1.2$ years. All workers could define noise. Ninety (53\%) workers attributed NIHL to noisy work environment. Excessive noise levels were in Plant Processing (94 dBA), Underground Mining (102 dBA) and (Underground Workshop (103 dBA). Sixty two $(36.7 \%)$ workers had NIHL. NIHL increased as a function of age (chi square $=30.99 \mathrm{df}=3 \mathrm{p}<0.01)$ and was associated with work area (chi square $=24.96 \mathrm{df}=5 \mathrm{p}<0.01$ ). Observed workers took heed of noise warnings. There was no documented hearing conservation program at the mine.

Conclusion: The prevalence of NIHL of $37 \%$ is high. Age and work area were associated with NIHL. Studies reported that age tends to distort the relationship between noise exposure and NIHL. Mine management should institute a hearing conservation program to protect employees against hazardous noise. Management may meanwhile use administrative controls and adhere to permissible exposure limits according to the noise regulations.

African Health Sciences 2013; 13(4): 899 - 906 http://dx.doi.org/10.4314/ahs.v13i4.6
\end{abstract}

\section{Introduction}

Hearing impairment is the most frequent sensory deficit in human population. Globally, over 275 million people are affected and $80 \%$ of them are in low- and middle income countries ${ }^{1}$. Hearing loss gives rise to problems in recognizing speech, especially in difficult environments, reduced ability to detect, identify and localize sounds quickly and reliably. These sounds may be warning or alarm signals, as well as music and birds singing. Having this communicative disability affects the hearingimpaired people and people in their environment e.g. family members and fellow workers. Studies have shown that uncorrected hearing loss gives rise to poorer quality of life, related to isolation, reduced social activity, and a feeling of being excluded, leading to an increased prevalence of symptoms of depression ${ }^{2}$.

*Corresponding author:
Addmore Chadambuka
Department of Community Medicine
University of Zimbabwe
Zimbabwe
Email: achadambuka1@yahoo.co.uk

African Health Sciences Vol 13 Issue 4 December 2013
The World Health Organisation Programme for the Prevention of Deafness and Hearing Impairment is concerned with developing and promoting strategies for prevention of the major causes of hearing impairment and deafness which constitute public health problems. The World Health Organisation (WHO) carried out an assessment of the global disease burden from occupational noise. Noisy workplaces have a heavy impact on health around the world. Millions of years of healthy life are lost due to occupational noise-induced hearing loss. Worldwide, 22 per cent of disabling hearing loss in men is caused by occupational noise. Men are generally more exposed than women to excessive noise in the workplace ${ }^{3-4}$.

In developing countries occupational noise accounted for about 3.8 million years of healthy life on an annual basis in 2000 compared to 0.3 million years in developed countries ${ }^{5-6}$ Noise induced hearing loss represents a much heavier burden in developing countries than in developed regions of the world. The difference is mainly due to lack of noise prevention programs and awareness of the consequences of the excessive noise exposure ${ }^{6}$. Social 
noise exposure has been increasing over the last 10 to 15 years, including in more developed countries. This occurred particularly through attendance at discos and to a lesser extent through the use of personal stereos ${ }^{7}$ but has been found without significant effect on hearing threshold levels ${ }^{8}$

Summary statistics on noise exposure are not available for most industrializing and nonindustrialized countries; however, high occupational noise exposure levels were reported in 17 studies conducted in 12 countries in South America, Africa and Asia. These high noise levels occurred in a wide range of workplaces, including manufacture of foods, fabrics, printed materials, metal products, drugs, watches and in mining. Many of these studies reported hearing losses in exposed workers ${ }^{6}$.

In Zimbabwe, the Factories and Works Act Chapter 14:08 requires employers to take all practical steps for the health of employees and persons lawfully on the premises. All employees should be properly trained and when under supervision, are properly supervised by a competent person, provided with personal protective equipment and clothing where necessary and that these are used, safeguarded against dangerous machinery, hazardous processes, noise, dust and provided with a safe and healthy work environment ${ }^{9}$.

Noise induced hearing loss (NIHL) is within the top five occupational illnesses in Zimbabwe and among the top three compensable occupational illnesses after backache and pneumoconiosis ${ }^{10}$. Zimbabwe has a law which specifically protects workers exposed to several hazards in industry including mining establishments ${ }^{11}$.

Mine $\mathrm{X}$ is a major underground mining concern in Zimbabwe. NIHL is one major problem facing mining workers today. The occupational environment at the mine is filled with heavy machinery and equipment for drilling and crushing, and processes that produce potentially hazardous noise. Twenty nine workers $(5.5 \%)$ at the mine $(n=524)$ complained about loss of hearing at the mine clinic over a period of two years. The latest survey conducted by the Ventilation Officer at the mine showed that noise level was between $64 \mathrm{~dB}(\mathrm{~A})$ in administration areas and $108.5 \mathrm{~dB}(\mathrm{~A})$ in underground mining sections. At the Mine, the standard noise acceptable is $85 \mathrm{~dB}$ (A) and the Factories and Works (General) Regulations Section 6 prescribes an exposure limit to noise of $90 \mathrm{~dB}$ (A) for an 8 hour shift. There are two shifts that operate at the whole mine that work each an extra four hours on overtime which is against the permissible exposure limit (PEL).

Old audiometry records show the mine at once compensated three employees on medical grounds after suffering NIHL costing the company US $\$ 2$ million in claims.

The National Social Security Authority (NSSA) suspended certain operations in 110 firms for failing to comply with occupational safety and health laws in $2010^{12}$. There was need to investigate and understand the occupational noise levels, while also assessing the effectiveness of occupational health and safety programs in place.

This study of NIHL at the Mine was important to determine the prevalence of this occupational illness and gather baseline information for further studies and ensure legal compliance and improvement of internal operations to reduce danger (hearing impairment), downtime, and as part of Occupational, Health and Safety Management System (OHSAS)18001. We determined the prevalence of noise induced hearing loss among employees at the Mine.

\section{Methods}

We conducted a descriptive cross sectional study. This included a walk through survey and an audiometry testing. The study was conducted at a mining town in Zimbabwe. The study population consisted of all 524 mine employees. Workers were proportionally selected to represent all the mine departments or working areas. We listed workers from each department and randomly selected workers proportional to department size from these lists to participate in the study. We used a sample size of 169 workers assuming a prevalence of noise induced hearing loss to be $3 \%$ and a worst acceptable result of $5 \%$ at $95 \%$ confidence interval.

Audiometry testing was done by trained research assistants from 18 February 2012 to 08 March 2012 and the degree and type of NIHL was classified according to Goodman ${ }^{13}$ and Cahart ${ }^{14}$. The procedure adopted included a detailed case history and audiometry. The audiometric tests were conducted in a test booth with an ambient noise of $30 \mathrm{~dB}$ (A) located at the mine clinic. The tests were conducted at frequencies from $125 \mathrm{~Hz}$ through to $8000 \mathrm{~Hz}$ in octaves using a calibrated Kamplex Audiometer (Model 27) and recorded on a standard audiogram form (figures 1 and 2). 


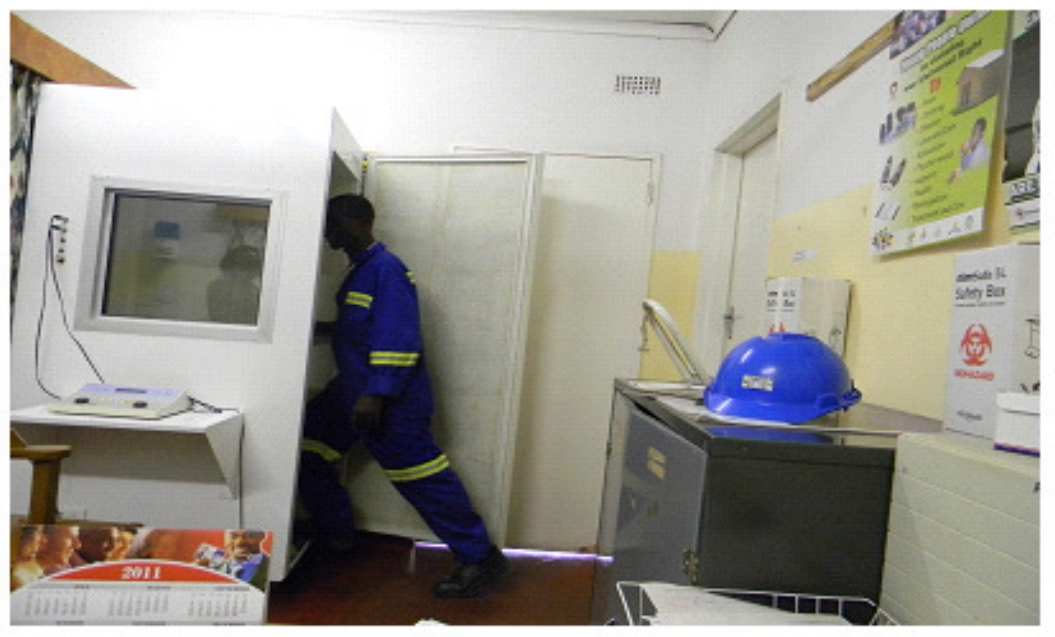

Figure 1: Participant entering into audio booth for audiometric testing

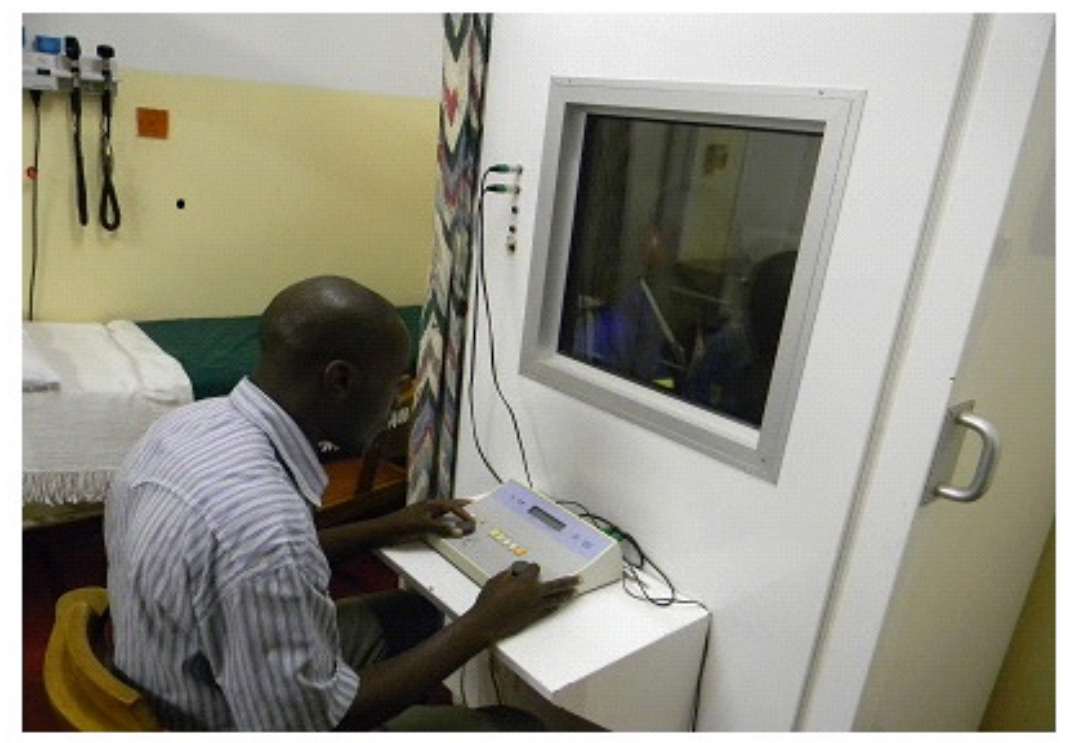

Figure 2: Technician selecting frequencies and manipulating hearing level during audiometric testing

A structured questionnaire was used to collect data from study participants on demographic variables and knowledge of hearing protection and its use by trained research assistants. We reviewed medical records for 169 workers to check for symptoms related to NIHL. An observation checklist was to capture practices of workers in relation to noise prevention and control while at work. The practices observed included observing noise warning signs when approaching noisy areas; use of earplugs and earmuffs or other noise controls when using noisy machinery or working in a noisy areas and storage of ear plugs and earmuffs. A participant observer was used to capture practices so that workers would not know they were being observed. We measured noise levels at different work sites. Readings were done by three trained independent readers and the average noise level was calculated. Two key informants from the office of health and safety were interviewed on noise control.

We analysed quantitative data using EPI Info 3.5.1 to generate frequencies. Qualitative data was analysed manually. We obtained permission to conduct the study from Mine Management and the ethical clearance from the University of Zimbabwe Ethics Committee. We obtained informed written consent from our study participants to conduct audiometric testing and respond to questions and confidentiality was assured. We informed Management of workers affected by noise induced hearing loss for corrective action. Health education was given on the importance of using hearing protection where it's required and the consequences of not using it. 


\section{Results}

We conducted face-to-face interviews with 169 workers. Of the 169 persons interviewed only 11 were women and 158 were men (table 1). The mean age for the workers was 34.8 years (standard deviation (ó $=7.6$ ) and the mean duration of exposure to noise was 7.5 years (ó $=1.2)$. Forty seven $(27.8 \%)$ workers had attained the Zimbabwe Junior Certificate of Education. Ninety seven (57.3\%) of the workers interviewed had attained Ordinary Level education coupled with a significant number of inservice certificates of competence and attendance. Thirteen (7.7\%) workers had attained Advanced Level, the rest (12) 7.2\% had attained diplomas and competence certificates from the Ministry of Mines.

Table 1: Distribution of mining employees and the number interviewed

\begin{tabular}{lcc}
\hline Work area & $\begin{array}{c}\text { Number } \\
\text { of } \\
\text { workers }\end{array}$ & $\begin{array}{c}\text { Number } \\
\text { interviewed }\end{array}$ \\
\hline Administration & 43 & 7 \\
Plant Processing & 48 & 13 \\
Plant Engineering & 35 & 9 \\
Technical Services & 64 & 23 \\
Underground Mining & 215 & 83 \\
Underground Workshop & 25 & 14 \\
Contractors & 94 & 20 \\
Total & 524 & 169 \\
\hline
\end{tabular}

Knowledge on noise induced hearing loss

A sample of 169 mine workers (84 from underground and 85 from surface operations) were interviewed. All the workers could define noise with $96(56.9 \%)$ reporting that it was sound that interfered with hearing normal conversation and $63(37.2 \%)$ reporting it as unwanted sound. One hundred and seven $(63.3 \%)$ per cent of the workers reported having heard of NIHL before. Ninety $(53.2 \%)$ workers attributed NIHL to working in noisy environments, $69(40.8 \%)$ to improper or non-use of hearing protection and $10(5.9 \%)$ to intermittent but very loud sounds. About 140 (82.8\%) employees reported using hearing protection devices because they are always exposed to noise and $13(7.5 \%)$ reported using hearing protection whenever they entered a noise designated area. One hundred and sixteen $(68.6 \%)$ workers reported using earplugs while $53(31.4 \%)$ used earmuffs. About 160 (94.7\%) workers reported they were trained in using hearing protection devices.

\section{Observation of work practices}

The observations recorded in the 7 days' work practice observation checklist indicate that the optimum operating conditions for the prevention of NIHL were achieved. Most workers (90 $\pm 5 \%$ ) observed noise warning signs and wore their hearing protection in all noise designated areas. None was observed using noisy machinery without hearing protection.

\section{Noise survey at the mine}

Some mine areas had excessive noise levels (Plant Processing 94 dB), (Underground Mining 102 dB) and (Underground Workshop103 dB) since the acceptable level is $90 \mathrm{~dB}$ for an 8 -hour period. These areas had no engineering control measures in place to reduce noise levels. The noise levels measured at different sites at the mine are shown in table 2 .

\section{Audiometry Results}

A total of 169 workers from 19 to 63 years of age were seen on site at Mine Clinic, had both ears tested for noise induced hearing loss. Sixty two (36.7\%) workers had noise induced hearing loss. This was classified as mild in $41(66.1 \%)$, moderate in 17 $(27.4 \%)$ and severe in $4(6.5 \%)$ of the affected workers. No pre-exposure audiograms were available for the workers were available for comparison as baseline hearing level. NIHL tended to increase as a function of age. The age distribution for workers observed to have noise induced hearing loss at $4 \mathrm{kHz}$ is shown in table 3 . There is a direct relationship between NIHL and the duration of exposure. The longer the duration of exposure to noise is, higher the prevalence of NIHL. The relationship between the duration of exposure to noise and the development of hearing loss at $4 \mathrm{kHz}$ is shown in table 4. 
Table 2: Average noise levels $\mathrm{dB}(\mathrm{A})$ Measured Underground and on Surface at the Mine, 2011

\begin{tabular}{|c|c|c|c|c|}
\hline Location & $\begin{array}{l}\text { Noise reading } \\
1\end{array}$ & $\begin{array}{l}\text { Noise reading } \\
2\end{array}$ & $\begin{array}{l}\text { Noise reading } \\
3\end{array}$ & $\begin{array}{c}\text { Average noise } \\
\text { dB(A) }\end{array}$ \\
\hline \multicolumn{5}{|l|}{ Mining underground } \\
\hline 725 ramp booster fan & 109.0 & 108.3 & 107.0 & 108.1 \\
\hline 800x5pump station & 100.0 & 99.0 & 102.0 & 100.3 \\
\hline 815-580 DD2 Exhaust fan & 104.0 & 102.0 & 108.8 & 104.9 \\
\hline $815-635 \mathrm{x} / \mathrm{c}$ forces fan & 96.0 & 97.0 & 95.6 & 96.2 \\
\hline $815-670$ x/c (Rig 22) & 109 & 105 & 110 & 108 \\
\hline LHD10@800-950slot & 105 & 109 & 110.2 & 108.1 \\
\hline 920 diamond drilling machine & 96 & 99 & 99 & 98.0 \\
\hline South ramp 900 pump station & 100 & 98 & 100.8 & 99.6 \\
\hline 860 south ramp pump station & 95.8 & 96 & 97 & 96.3 \\
\hline UG workshop & 108.4 & 104.0 & 102 & 104.7 \\
\hline UG boiler shop & 102 & 99 & 105 & 102.0 \\
\hline Workshop compressor & 103 & 100 & 106 & 103.0 \\
\hline \multicolumn{5}{|l|}{ Technical services } \\
\hline Grader & 90 & 94 & 92.4 & 92.1 \\
\hline TD 20 & 104 & 102 & 108 & 104.6 \\
\hline Electrical workshop & 69 & 75 & 71 & 71.6 \\
\hline Underground offices & 69 & 66 & 63 & 66 \\
\hline Stores & 74 & 69 & 68 & 70.3 \\
\hline Lab sampling preparation room & 109 & 105 & 101 & 105 \\
\hline \multicolumn{5}{|l|}{ Administration } \\
\hline Main offices & 56 & 55 & 54 & 55 \\
\hline Civils workshop & 100 & 102 & 101 & 101 \\
\hline Clinic & 55 & 55 & 56 & 55.3 \\
\hline \multicolumn{5}{|l|}{ Plant processing } \\
\hline Plant floor & 106 & 100 & 109 & 105 \\
\hline Plant sag mills & 99 & 109 & 105 & 104.3 \\
\hline Plant chutes & 89 & 93 & 86 & 89.3 \\
\hline CV 3A & 96 & 95 & 93 & 94.6 \\
\hline Plant boiler shop & 94 & 96 & 95 & 95 \\
\hline Dewatering pumps & 97 & 98 & 99 & 98 \\
\hline Plant processing pumps & 95 & 95 & 92 & 94 \\
\hline Tank 0 & 91 & 87 & 89 & 89 \\
\hline Tank 1 & 90 & 91 & 87 & 89.3 \\
\hline Tank 5 & 85 & 86 & 88 & 86.3 \\
\hline Tank 6 & 95 & 96 & 94 & 95 \\
\hline High security gate & 85 & 83 & 88 & 85.3 \\
\hline Carbon screen & 88 & 91 & 87 & 88.6 \\
\hline CIL spillage pumps & 95 & 96 & 94 & 95 \\
\hline Plant compressor room & 96 & 94 & 95 & 95 \\
\hline High security gate & 85 & 83 & 88 & 85.3 \\
\hline Plant mechanical, electrical shop & 69 & 73 & 70 & 70.6 \\
\hline Crusher pad & 87 & 86 & 85 & 86 \\
\hline New tailings budge pumps & 102 & 106 & 105 & 104.3 \\
\hline Crusher control room & 87 & 86 & 85 & 86 \\
\hline
\end{tabular}

Data from interviews showed that $140(82.8 \%)$ employees reported using hearing protective devices but despite reported use of protective devices, audiometry testing found $62(36.7 \%)$ had NIHL. Most workers 36 (58.1\%) affected by NIHL worked underground. Both key informants indicated that there was no documented noise hearing conservation program. 
Table 3: Age Distribution among Workers with NIHL

\begin{tabular}{llll}
\hline Worker's Age & No. Tested & $\begin{array}{l}\text { No. with } \\
\text { NIHL (\%) }\end{array}$ & $\begin{array}{l}\text { No. without } \\
\text { NIHL (\%) }\end{array}$ \\
\hline $19-29$ & 27 & $4(15)$ & $23(85)$ \\
$29.1-39$ & 93 & $25(27)$ & $68(73)$ \\
$39.1-49$ & 37 & $23(62)$ & $14(38)$ \\
$49.1+$ & 12 & $10(83)$ & $2(17)$ \\
Total & 169 & $62(37)$ & $107(63)$ \\
\hline
\end{tabular}

Chi square $=30.99, \mathrm{df}=3, \mathrm{p}<0.01$

Table 4: Relationship between duration of exposure and NIHL

\begin{tabular}{llll}
\hline $\begin{array}{l}\text { Duration of } \\
\text { exposure (Years) }\end{array}$ & No. Tested & $\begin{array}{l}\text { No. with } \\
\text { NIHL (\%) }\end{array}$ & $\begin{array}{l}\text { No. without } \\
\text { NIHL (\%) }\end{array}$ \\
\hline $1-5$ & 85 & $23(27)$ & $62(73)$ \\
$6-10$ & 42 & $18(43)$ & $24(57)$ \\
$11-15$ & 33 & $16(48)$ & $17(52)$ \\
$16-20$ & 9 & $5(55)$ & $4(45)$ \\
Total & 169 & $62(37)$ & $107(63)$ \\
\hline
\end{tabular}

Chi square $=7.44, \mathrm{df}=3, \mathrm{p}<0.05$

\section{Discussion}

The prevalence of NIHL (36.7\%) is higher as compared to the prevalence reported in other studies. The high prevalence at this Mine case could have been attributed to the non-existence of a documented hearing conservation program to protect the workers other than the use of PPE and lack of engineering controls. Because of the absence of baseline hearing levels, no conclusion can be made on the hearing threshold elevations recorded in the 62 workers. Some of them could have joined the company already with existing NIHL from their previous jobs. Amedofu et alin their study of hearing impairment among workers in gold mining in Ghana reported a prevalence of $23 \%$ in a population of 252 workers ${ }^{15}$. Masaka et al who determined the prevalence of NIHL at a Nickel mine in Zimbabwe showed that the prevalence of NHIL was $27.4 \%$ in a population of 168 employees which is much lower than what we found in this study ${ }^{16}$.

The generally accepted standard regulation in most countries is that a noise level of more than $85 \mathrm{dBA}$ for an 8 -hour daily exposure is potentially damaging. In Zimbabwe, The Factories and Works (General) Regulations, 1976 Part 2 of the Health and Safety section prescribes that, "No person shall be exposed to sound levels exceeding the limits, $90 \mathrm{dBA}$, unless such person has been supplied with ear protectors" 17 . Noise levels in several working areas were higher than recommended. This may be a reflection that noise producing processes or equipment do not have adequate noise control measures.

Whilst $100 \%$ of the workers could define noise and knew that it caused hearing loss among the workers, the reported use of protective devices was not equally high, $(82.8 \%)$, the actual practices as observed showed that $100 \%$ compliance to hearing protective devices usage was rarely achieved. This can be attributed to the worker attitudes and sometimes forgetfulness.

I Age and duration of exposure in this study were related to NIHL. Other studies have reported that age tends to distort the relationship between exposure to noise and noise induced hearing $\operatorname{loss}^{18}$ 19. With increase in age, there are changes in hearing due to age (presbycusis) and this will add on to any existing NIHL giving the impression that older individuals suffer a greater degree of deafness than the younger workers. NIHL is a result of the total noise exposure over that person's lifetime and not just length of a single exposure to noise. The longer the exposure at excessive noise level the greater the degree of NIHL.

NIHL has been reported to be a function of work area with workers in noisy areas being affected most $^{20}$. In this study, some workers were found with NIHL in areas normally thought to be 
free from noise. This may be because those affected by NIHL are usually rotated to the noise free areas to prevent further exposure.

\section{Conclusion}

Occupational NIHL is a problem for the mine workers. Workers in plant processing, plant engineering and underground workshop were exposed to hazardous noise. The mine management should institute a hearing conservation programme to protect employees against hazardous noise. The hearing conservation must begin by providing each individual with information. The mine management should install engineering controls in areas exceeding permissible noise levels. Alternatively management may meanwhile use administrative controls and adhere to permissible exposure limits according to the noise regulations.

\section{Acknowledgements}

We acknowledge Locadia Muresherwa for the her moral support, Wonder Nyoni for his mentorship during the study and giving us access to mine facilities, Regina Johns, the Sister in Charge at the mine clinic, $\mathrm{Mr}$ and Mrs Mususa who gave us financial support. We want to thank Tinei Carlos Mwashita and Tafadzwa Chimweta who participated in administering the questionnaires, conducting the noise survey and audiometry. We would like to acknowledge all the study participants for without them, the study would have not been possible.

\section{Author contributions}

Freddy Mususa: He was responsible for the conception of the problem, design, collection, analysis and interpretation of data and drafting the final article.

Addmore Chadambuka: Participated in the design, analysis and interpretation of data and drafting the final article and critical review of the final draft.

Shamiso Muteti: She was responsible for the conception of the problem, design, analysis and interpretation of data and drafting the final article.

\section{References}

1. World Health Organization. Deafness and Hearing Impairment. Fact Sheet no 300, February 2012. http://www.who.int/mediacentre/ factsheets/fs300/en/index.html accessed 30/ 07/2012
2. Arlinger S. Negative Consequences of Uncorrected Hearing Loss-A Review. Int J Audiol. 2003 Jul; 42 Suppl 2:2S17-20.

3. http://www.press.hear-it.org/The-globalburden -of-noise-induced-hearing-loss accessed $30 / 7 / 2012$

4. World Health Organization. Occupational Health: A Manual for Primary Health Care Workers.http:// www.who.int/ occupational_health/regions/en/ oehemhealthcareworkers.pdf accessed 19/11/ 2012

5. Nelson DI, Concha-Barrientos M, Driscoll T, Steenland K, Fingerhut M, Punnet L et al. The Global Burden of Selected Injuries and Injury Risks: Methodology and Summary

6. Nelson DI, Nelson RY, Concha-Barrientos M and Fingerhut M. The Global Burden of Occupational Noise Induced Hearing Loss. American Journal of Industrial Medicine 2005; 48(6): 400-408

7. Olishifski JB. Occupational Medicine. Third Edition: 1998

8. Smith P, Davis A. Social Noise and Hearing Loss. The Lancet, Vol353 Issue 9159 page 1185, 1999. http://www.thelancet.com/journals/lancet/ article/PIIS0140-6736(05)74404-4/fulltext accessed 30/7/2012

9. Zimbabwe Government. Factories and Works Act Chapter 14:08. Government Printers 1996

10. Zimbabwe Government. 1997 Statistical Yearbook; Central Statistical Office: 1997.

11. National Social Security Act 1990. Zimbabwe Government. Statutory Instrument 68/1990; Government Printers: 1990.

12. National Social Security Authority Closes Down 110 Firms for Flouting Occupational Health Laws. The Sunday Mail, 9 January 2011

13. Goodman A. Reference New Levels for Pure Tone Audiometers: American Speech and Hearing Association (ASHA). 1965; 7: 262-3

14. Cahart R. Classifying Audiograms: An Approved Method of Classifying Audiograms. Laryngoscope, 1945 55; 13

15. Amedofu GK. Hearing Impairment among Workers in Gold Mining in Ghana. African Journal Health Sciences Volume 9 Number 1-2 January- June 2002.

16. Masaka E. The Prevalence of Noise Induced Hearing Loss at a Nickel Mine in Zimbabwe. Master of Public Health (Occupational Hygiene) 
Dissertation. University of Witwatersrand http:/ /www.wits.ac.za accessed 10/10/2012

17. Zimbabwe Government. Factories and Works (General) Regulations, 1976. Government Printers, 1996.

18. Galow E and Glorig A. Permanent Threshold Shift Changes Produced by noise Exposure and Ageing. American Industrial Hygiene Association. 1964;12 705-724;
19. Ali A, Garandawa HI, Nwawolo CC and Somefun OO. Noise Induced Hearing Loss at Cement Compant, Nigeria. Online J. Med Med Sci. Res. 2012; 1(3): 49-54.

20. Wahab U and Zaidi HS. Noise Induced Hearing Loss in Pakistan. Pakistan Journal of Otorbinolaringology. 1997; 75-77. 